\title{
Median canaliform dystrophy of Heller at thumb level
}

\section{Kaoutar Achehboune, Sara Dahhouki, Zakia Douhi, Sara Elloudi, Hanane Baybay, Fatima Zahra Mernissi}

Department of Dermatology, Hassan II Hospital University, Fez, Morocco

Corresponding author: Dr. Kaoutar Achehboune, E-mail: achehboune.kaoutar@gmail.com

Child 12 years old, having a tic history of cuticle regrowth of thumbs bilaterally. No history of use of oral retinoids or other drugs, or history of contact with irritants or allergens was present. No nail disorder or psychiatric disorder in the family. Consult for bilateral nails lesions. On examination, a single medial longitudinal groove with transverse furrows from the medial side on either side achieving a fir appearance present on both thumbnails, above, the right thumbnail (Fig. 1). The medial groove extended from the proximal fold to the distal edge of the nail. The Lunula seemed to be enlarged in size. No skin lesions present elsewhere. The systemic examination was without particularity. The diagnosis of median nail dystrophy has been made on a clinical basis. The patient was advised not to bite their nails. A psychiatric consultation was recommended; advice was offered to the patient. The evolution was good after 6 months.

Median canaliform dystrophy (MCD) of Heller is a rare entity characterized by a midline or a paramedian ridge or split and canal formation in nail plate of one or both the

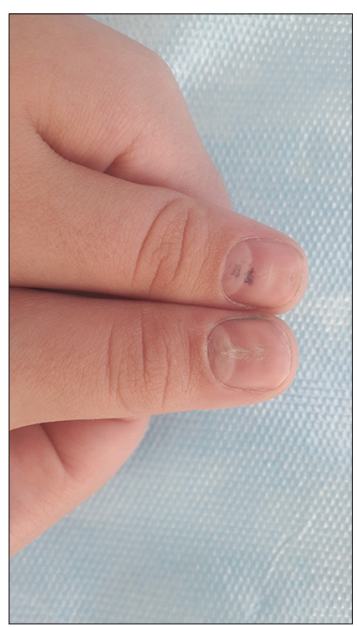

Figure 1: Heller medial canaliform dystrophy at the bilateral thumb. thumb nails. It is an acquired condition resulting from a temporary defect in the matrix that interferes with nail formation [1]. The condition is diagnosed based on its clinical features. It results from a temporary defect in the nail matrix, following dyskeratinization or focal infection, or due to self-inflicted trauma to the nail plate, nail matrix or nail bed [2]. A few cases have been attributed to oral retinoid use also [3]. Presents with small cracks or fissures that extend laterally from the central canal or split towards the nail edge giving the appearance of an inverted fir tree or Christmas tree, usually symmetrically affecting the thumb nails mainly [4]. Treatment of median nail dystrophy includes injectable triamcinalone acetonide, topical $0.1 \%$ tacrolimus, and tazarotene $0.05 \%$, which is many a times challenging for a dermatologist. Psychiatric opinion should be taken when associated with the depressive, obsessivecompulsive, or impulse-control disorder [1].

\section{Consent}

The examination of the patient was conducted according to the Declaration of Helsinki principles.

\section{REFERENCES}

1. Kota R, Pilani A, Nair PA. Median nail dystrophy involving the thumb nail. Indian J Dermatol. 2016;61:120.

2. Sweeney SA, Cohen PR, Schulze KE, Nelson BR. Familial median canaliform nail dystrophy. Cutis. 2005;75:161-5.

3. Dharmagunawardena B, Charles-Holmes R. Median canaliform dystrophy following isotretinoin therapy. Br J Dermatol. 1997;137:658-9.

4. Wu CY, Chen GS, Lin HL. Median canaliform dystrophy of Heller with associated swan neck deformity. J Eur Acad Dermatol Venereol. 2009;23:1102-3.

Copyright by Kaoutar Achehboune, et al. This is an open access article distributed under the terms of the Creative Commons Attribution License, which permits unrestricted use, distribution, and reproduction in any medium, provided the original author and source are credited.

Source of Support: Nil, Conflict of Interest: None declared.

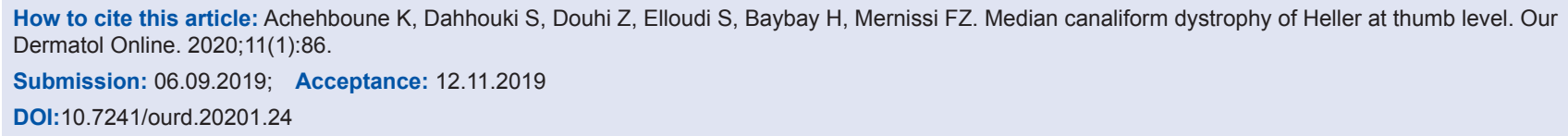

